\title{
The birth of the elephant trunk technique
}

\author{
Hans G. Borst, MD
}

Surgery on the aorta, except for its arch portion, had been well established in the sixth decade of the past century. My personal attention was drawn to the arch when consulting on a patient in 1963, who had experienced multiple shrapnel injuries in World War II. He now presented in severe heart failure due to a traumatic fistula between the mid-aortic arch and the innominate vein with a huge pseudoaneurysm. To repair this lesion, we decided to use circulatory arrest in deep hypothermia, a method that then had been practiced mainly in congenital lesions.

Using a left-sided approach, a fist-size, vigorously pulsating aneurysm was encountered in the subaortic mediastinum. On extracorporeal circulation, the patient was cooled to a nasopharyngeal temperature of $19.5^{\circ} \mathrm{C}$, and the circulation was stopped for 10 minutes. Most of the aneurysm was removed, and the 2 orifices of the fistula were closed by direct suture. ${ }^{1}$ The patient had an uneventful recovery. Anecdotal as this operation might appear, it was 1 of the first successful interventions on the aortic arch in deep hypothermic circulatory arrest—and possibly the last 1 up to now for an arteriovenous fistula in this location.

About 10 years later, additional research in deep hypothermia and circulatory arrest, as well as increasing clinical experience, had firmly established surgery on the aortic arch. $^{2,3}$ One serious problem, however, remained: the high risk of multiple-stage operations required for the frequently encountered aneurysms extending distally from the aortic arch. In particular, mobilization of the previous graft-toaorta anastomosis during the second-stage procedure was cumbersome and endangered the surrounding structures. In addition, the insertion of a separate downstream graft required prolonged aortic clamp times.

In 1982, I was confronted with 2 patients in their mid-40s with the mega-aorta syndrome. In view of the problems previously encountered with such lesions, we decided to replace the aortic arch with a long graft, whose free "elephant trunk" extension was to be suspended freely in the distal aorta. During the subsequent operative act, the downstream aorta was clamped proximally, and the "elephant trunk" was identified and sutured to the desired distal landing site. In 1 of the patients, the arch and part of the descending aorta were replaced in 2 stages, and the other patient underwent additional thoracoabdominal aortic replacement, again using the "elephant trunk" principle. Both patients survived uneventfully. These operations were published under the somewhat curious heading of "How to do it." 4

The bright future of the elephant trunk technique could not be anticipated at that time. In fact, Stanley Crawford, the most experienced surgeon in the treatment of aortic pathology at that time, was quite skeptical when I first explained the elephant trunk technique to him. It did not take long, however, until his group was using this approach extensively. There probably is no method that cannot be improved. We had performed the distal graft-to-aorta anastomosis using a continuous suture, working from within the vessel, with the "elephant trunk" advanced distally. It was Lars Svensson who simplified our approach by invaginating the trunk into the arch portion of the graft, using the resulting fold for the distal graft-to-aorta anastomosis. ${ }^{5}$ The trunk portion of the graft was thus out of the way while performing this connection and was advanced downstream just before completing the anastomosis. The "frozen elephant trunk" technique, recently described by my former coworker Mathias Karck, greatly expanded the scope of the original approach, because the aortic arch and downstream aorta could now be grafted in 1 operative act using hybrid prostheses. ${ }^{6}$

Looking back over the past 3 decades, I greatly enjoy that my initial observation of an elephant's trunk dangling in mid-air has triggered an ongoing surgical success story.

\section{References}

1. Borst HG, Schaudig A, Rudolph W. Arteriovenous fistula of the aortic arch: repair during deep hypothermia and circulatory arrest. J Thorac Cardiovasc Surg. 1964; 48:443-7.

2. Griepp RB, Stinson EB, Hollingsworth JF, Buehlar D. Prosthetic replacement of the aortic arch. J Thorac Cardiovasc Surg. 1975;70:1051-63.

3. Crawford ES, Saleh SA, Schwessler JS. Treatment of aneurysms of the transverse aortic arch. J Thorac Cardiovasc Surg. 1979;78:383-93.

4. Borst HG, Walterbusch G, Schaps D. Extensive aortic replacement using "elephant trunk" prosthesis. J Thorac Cardiovasc Surg. 1983;31:37-40.

5. Svensson LG. Rationale and technique for replacement of the ascending aorta, arch, and distal aorta using a modified elephant trunk procedure. J Cardiac Surg. 1992;7:301-12.

6. Karck M, Chavan A, Khaladj N, et al. The frozen elephant trunk technique for the treatment of extensive thoracic aneurysms: operative results and follow up. Eur J Cardiothorac Surg. 2005;28:286-90.

Disclosures: Author has nothing to disclose with regard to commercial support.

Address for reprints: Hans G. Borst, MD, Widenmayerstrasse 7, Munich 80538, Germany (E-mail: hgborst@gmx.net).

J Thorac Cardiovasc Surg 2013;145:44

$0022-5223 / \$ 36.00$

Copyright $\Subset 2013$ Published by Elsevier Inc. on behalf of The American Association

for Thoracic Surgery

http://dx.doi.org/10.1016/j.jtcvs.2012.10.002 